\title{
Halobacteriovorax, an underestimated predator on bacteria: potential impact relative to viruses on bacterial mortality
}

\author{
Henry N Williams ${ }^{1,5}$, Despoina S Lymperopoulou ${ }^{1,5,6}$, Rana Athar ${ }^{1,5,7}$, Ashvini Chauhan ${ }^{1}$, \\ Tamar L Dickerson ${ }^{1}$, Huan Chen ${ }^{1}$, Edward Laws ${ }^{2}$, Timkhite-Kulu Berhane ${ }^{1}$, \\ Adrienne R Flowers ${ }^{3}$, Nadine Bradley ${ }^{1}$, Shanterial Young ${ }^{1}$, Denene Blackwood ${ }^{4}$, \\ Jacqueline Murray ${ }^{1}$, Oladipupo Mustapha ${ }^{1}$, Cory Blackwell ${ }^{1}$, Yahsuan Tung ${ }^{1}$ \\ and Rachel T Noble ${ }^{4}$ \\ ${ }^{1}$ School of the Environment, Florida Agricultural and Mechanical University, Tallahassee, FL, USA; ${ }^{2}$ School \\ of the Coast \& Environment, Department of Environmental Sciences, Louisiana State University, Baton Rouge, \\ LA, USA; ${ }^{3}$ Gulf Coast Research Laboratory, University of Southern Mississippi, Ocean Springs, MS, USA and \\ ${ }^{4}$ Institute of Marine Sciences, University of North Carolina at Chapel Hill, Morehead City, NC, USA
}

\begin{abstract}
Predation on bacteria and accompanying mortality are important mechanisms in controlling bacterial populations and recycling of nutrients through the microbial loop. The agents most investigated and seen as responsible for bacterial mortality are viruses and protists. However, a body of evidence suggests that predatory bacteria such as the Halobacteriovorax (formerly Bacteriovorax), a Bdellovibrio-like organism, contribute substantially to bacterial death. Until now, conclusive evidence has been lacking. The goal of this study was to better understand the contributors to bacterial mortality by addressing the poorly understood role of Halobacteriovorax and how their role compares with that of viruses. The results revealed that when a concentrated suspension of Vibrio parahaemolyticus was added into microcosms of estuarine waters, the native Halobacteriovorax were the predators that responded first and most rapidly. Their numbers increased by four orders of magnitude, whereas $V$. parahaemolyticus prey numbers decreased by three orders of magnitude. In contrast, the extant virus population showed little increase and produced little change in the prey density. An independent experiment with stable isotope probing confirmed that Halobacteriovorax were the predators primarily responsible for the mortality of the $V$. parahaemolyticus. The results show that Halobacteriovorax have the potential to be significant contributors to bacterial mortality, and in such cases, predation by Halobacteriovorax may be an important mechanism of nutrient recycling. These conclusions add another dimension to bacterial mortality and the recycling of nutrients.

The ISME Journal (2016) 10, 491-499; doi:10.1038/ismej.2015.129; published online 7 August 2015
\end{abstract}

\section{Introduction}

Bacteria represent the most numerically dominant group of organisms on Earth (Amaral-Zettler et al., 2010), and much effort has been devoted to understanding their functions in nature, their interactions with other prokaryotes and eukaryotes, and their role in the cycling of nutrients through the microbial

Correspondence: HN Williams, School of the Environment, Florida Agricultural and Mechanical University, 1515S Martin Luther King Jr Blvd, Tallahassee, FL 32307, USA.

E-mail: henryneal.williams@famu.edu

${ }^{5}$ These authors contributed equally to this work.

${ }^{6}$ Current address: University of California Berkeley, Department of Plant and Microbial Biology, 331 Koshland Hall, Berkeley, CA 94720, USA.

${ }^{7}$ Deceased.

Received 23 March 2015; revised 16 June 2015; accepted 24 June 2015; published online 7 August 2015 loop. A subset of this effort has been devoted to assessing the role of viruses and protists in bacterial mortality. Predation on bacteria in marine, estuarine and freshwater systems has been the subject of many studies in the past two decades (Proctor and Fuhrman 1990; Fuhrman and Noble 1995; Weinbauer and Höfle, 1998; Tsai et al., 2013), prompted largely by the report of Proctor and Fuhrman (1990) that there are $10^{6}$ viruses per $\mathrm{ml}$ of seawater in the world's oceans. These studies have shown viruses to be major causative agents of bacterial mortality, sometimes exceeding the importance and activity of protistan grazers in aquatic systems.

Predatory bacteria such as the Bdellovibrio and like organisms (BALOs) have been studied for decades, and evidence suggests a high potential for these micro-predators to have significant roles in bacterial cell death in aquatic systems. 
These predatory bacteria are propelled at high speed by a polar flagellum, attack their prey by penetrating its cell wall, lodge in the periplasm and kill their quarry. Within the periplasm the predator feeds and grows on the prey's cellular material, multiplies by segmenting, and lyses the remaining prey cell wall, releasing newly formed predators into the environment to repeat the cycle (Starr and Baigent 1966). Although relatively low in abundance, typically 0-50 plaque-forming units (PFU) per $\mathrm{ml}$ (Taylor et al., 1974; Varon and Shilo, 1980; Richards et al., 2013), compared with viruses, BALOs are ubiquitous globally. They have been isolated from oceans, seas, estuaries, salt lakes, ponds, freshwater systems and soils (Taylor et al., 1974; Williams, 1979; Sutton and Besant, 1994; Pineiro et al., 2004; Davidov et al., 2006; Pineiro et al., 2007). Furthermore, many bacteria, up to $80 \%$ of cultivable organisms in estuarine systems, have been reported to be susceptible to predation by BALOs (Rice et al., 1998). The only known mode of the growth and multiplication of wild-type BALOs is predation on other bacteria. Therefore, their wide distribution in nature can only be explained by active killing of prey bacteria. Hence, they contribute some proportion of bacterial mortality. However, their overall significance in bacterial predation has never been quantitatively determined. In particular, their role in nature relative to viruses has not been considered.

This study was designed to test the hypothesis that BALOs have the potential to have a major role in the predation and mortality of prey bacteria and in some circumstances may cause mortality comparable to that caused by viruses.

To test our hypothesis, we monitored the responses of autochthonous Halobacteriovorax (Koval et al., 2014) (formerly Bacteriovorax), a genus within the BALO group, and virus-like particles when challenged with an influx of a prey bacterium, Vibrio parahaemolyticus, in laboratory microcosms containing natural seawater. In a second experiment, stable isotope probing (SIP) (with labeled prey) was used to track specific interactions between the prey and predators.

\section{Materials and methods}

Details of all methods are provided in Supplementary Information Materials and Methods. In brief, surface water was collected on separate occasions from Apalachicola Bay (FL, USA) to establish microcosms for two different experiments (Challenge Experiments I and II, Figure 1). The water sample was filtered through $0.8-\mu \mathrm{m}$ membrane filters to remove debris and larger organisms (Figure 1a). Four $250-\mathrm{ml}$ aliquots of the filtrate were then removed, and each was dispensed into a 1-l flask. One of the flasks was designated as the experimental test microcosm and received an inoculum of an overnight-grown suspension of $V$. parahaemolyticus to yield an optical density (OD) of 0.7 at $600 \mathrm{~nm}$, which corresponds to $\sim 5 \times 10^{8}$ colony-forming units (CFU) per ml, as enumerated on SWYE agar. A second flask was prepared in the same manner, except that it was not inoculated with prey and served as the natural water (NW) control microcosm. To establish a prey control microcosm free of predators, a third flask was autoclaved to sterilize the water prior to adding the same volume of the prey suspension that was added to the test microcosm. To establish the final microcosm, we pre-filtered (0.1- $\mu \mathrm{m}$ filter) the water before dispensing it into the flask to assure the exclusion of Halobacteriovorax predators without removal of most viruses. The prey was then inoculated into the microcosm, which we designated the virus-prey control. V. parahaemolyticus strain P-5 was selected as prey, because it is found in saltwater systems and is known to be susceptible to both bacteriophage (Baross et al., 1978; Crothers-Stomps et al., 2010) and Halobacteriovorax. All microcosm flasks were shaken at room temperature, and changes in prey density were monitored by OD measurements at 24-h intervals for $120 \mathrm{~h}$. In the Challenge Experiment I, the Halobacteriovorax, V. parahaemolyticus and total bacteria were also monitored for population changes by quantitative PCR, as described in SI. Samples for enumeration of viruses were preserved with $0.02-\mu \mathrm{m}$ filtered formalin to a final concentration of $2 \%$. For virus counting, samples were stained with SYBR Gold as described by Chen et al. (2001) and counted by epifluorescence microscopy.

The challenge experiment II protocol (Figure 1b) was similar to the previous experiment, the primary difference being that stable-isotope-labeled $V$. parahaemolyticus were used as prey. The SIP-labeled prey microcosm was established by amending a suspension of the labeled prey into one of the flasks. To detect any alterations in the predation pattern resulting from the label, a second flask was inoculated with unlabeled $V$. parahaemolyticus prey for comparison with the labeled microcosm. Other control microcosms included a $V$. parahaemolyticus prey (SIP Vp) control microcosm, which consisted of a suspension of prey in autoclaved estuarine water, and a SIP virus control microcosm. The latter consisted of $0.1-\mu \mathrm{m}$ filtered estuarine water with native viruses amended with prey, but free of Halobacteriovorax and of other bacteria, which were removed by the filtration. Changes in Halobacteriovorax and $V$. parahaemolyticus densities were also monitored by changes in OD and enumeration of plaque (BALOs) and CFU, respectively. To monitor predation by Halobacteriovorax by molecular methods, DNA was extracted from 100$\mu \mathrm{l}$ aliquots of water from the experimental flask (see Supplementary Information). Then, ${ }^{13} \mathrm{C}$ DNA was separated from unlabeled DNA by density gradient centrifugation (Padmanabhan et al., 2003) and was amplified using both a universal primer GM5F (5'-CCTACGGGAGGCAGCAG-3') with a GC 
a

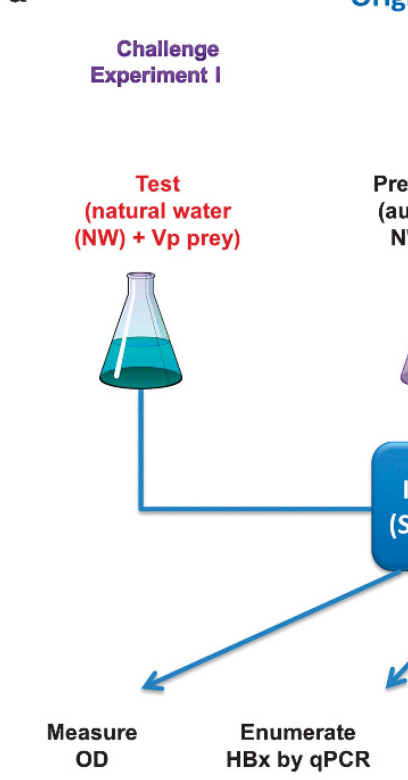

Original water sample

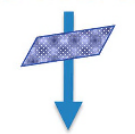

Filtration $(0.8 \mu \mathrm{m}$ polycarbonate filter)

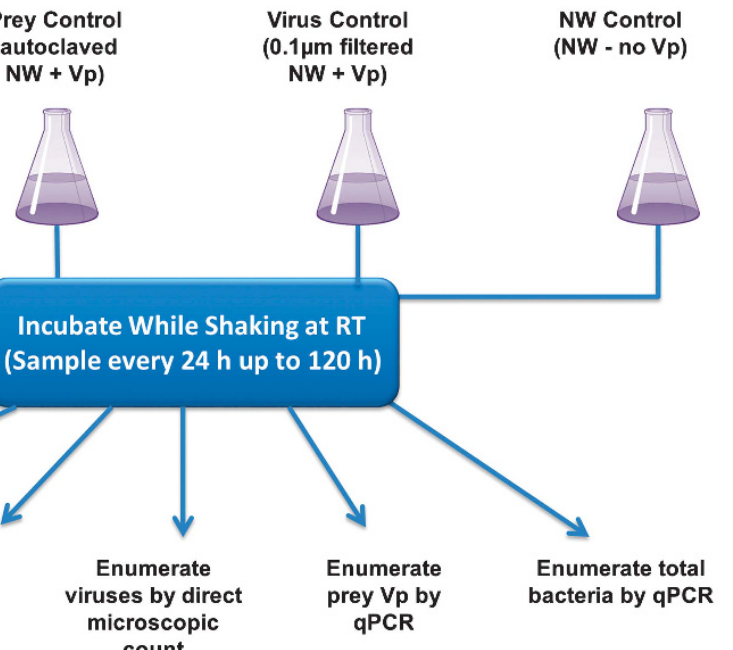

b Challenge Original water sample

Experiment II

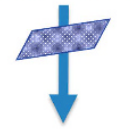

Filtration $(0.8 \mu \mathrm{m}$ polycarbonate filter $)$

$$
\text { SIP Test }
$$
(natural water (NW) + labeled prey)

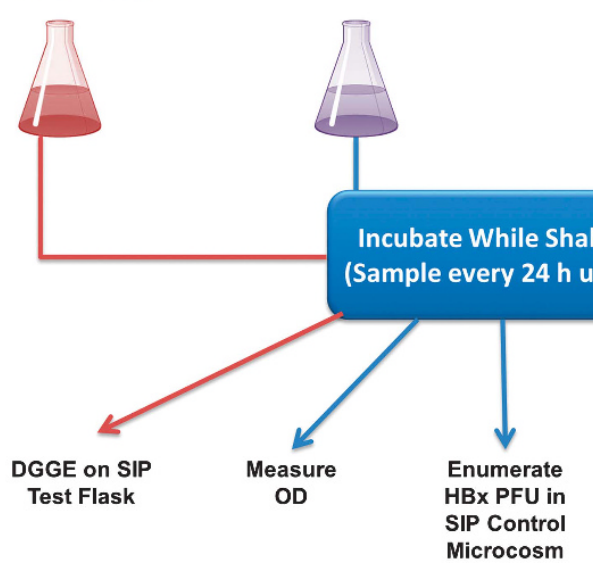
$\begin{array}{cc}\text { SIP Control } & \text { Prey Control } \\ \text { (NW + unlabeled Prey) } & \text { (autoclaved NW + Prey ) }\end{array}$
Virus Control $(0.1 \mu \mathrm{m}$ filtered NW + Prey)

Figure 1 A schematic flow chart of the experimental design used to establish and monitor the various microcosms. (a) Steps in the establishment of microcosms and monitoring by qPCR of targeted organisms, Halobacteriovorax (HBx), V. parahaemolyticus (Vp) prey and total bacteria, as well as monitoring of viruses by SYBR gold-based epifluorescence microscopy. (b) Steps in establishment of stable isotope and control microcosms and monitoring of the same targeted organisms as in a by measurements of optical density units (ODU) and/or enumeration by culture based methods and by stable isotope probing (SIP).

clamp attached to its $5^{\prime}$ end and 907R (5'-CCGT CAATTCCTTTGAGTTT-3') (Muyzer et al., 1995) and BALO-specific primers, Bac-676F (5'-ATTT CGCATGTAGGGGTA-3') and Bac-1442R (5'-GCCA CGGCTTCAGGTAAG-3'). Amplicons were run on a denaturing gradient gel electrophoresis (DGGE) gel gradient as described in Supplementary Information to characterize bacterial communities in the experimental flasks. Prominent bands were excised from the gel and sequenced. Analyses of DNA sequences were completed with the Basic Local Alignment Search Tool server from the National Center for Biotechnology Information (www.ncbi.nlm.nih.gov).

\section{Statistical analyses}

All statistical analyses and modeling were performed using the data from Challenge Experiment I. 
The abundance of predator and prey (log transformed) were analyzed by analysis of variance (ANOVA) followed by the post hoc Holm-Sidak test to detect significant differences among the numbers of bacteria in the various microcosm treatments when the data were judged to be normally distributed based on a Kolmogorov-Smirnov normality test. A $t$-test was used as appropriate to compare two groups of treatments when the data were normally distributed. Null hypotheses were rejected if the type I error probability $(p)$ was $<0.05$ (GraphPad Prism version 6.02 for Windows, GraphPad Software, La Jolla, CA, USA). The population dynamics of the $V$. parahaemolyticus and Halobacteriovorax were assumed to be describable by a simple predator-prey model as follows:

$$
\begin{aligned}
\frac{d V_{p}}{d t} & =-\left(G B+L V+M_{V}\right) V_{p} \\
\frac{d B}{d t} & =\left(f G V_{p}-M_{B}\right) B
\end{aligned}
$$

where $V_{\mathrm{p}}$ and $B$ are the numbers of $V$. parahaemolyticus and Halobacteriovorax, respectively, $M_{\mathrm{V}}$ and $M_{\mathrm{B}}$ are the corresponding mortality rates unrelated to grazing and viral lysis, $V$ is the number of viruses, $G$ is the grazing rate of Halobacteriovorax on $V$. parahaemolyticus (that is, the fraction of $V$. parahaemolyticus cells consumed per Halobacteriovorax cell per hour), $L$ is the rate of viral lysis of the $V$. parahaemolyticus (that is, the fraction of $V$. parahaemolyticus lysed per virus per hour), and $f$ is the number of Halobacteriovorax that emerge from a dead $V$. parahaemolyticus cell after its contents have been utilized by the Halobacteriovorax predator. The number of viruses was almost constant throughout the experiment and was interpolated at hourly intervals by fitting a straight line to the virus counts. After assigning initial values to $V_{\mathrm{P}}$ and $B$, we numerically integrated this model with a time step of one hour. We assigned a value of five to $f$ based on the work of Fenton et al. (2010).

\section{Results}

The results demonstrate that Halobacteriovorax were the first and most rapid responders to the influx of $V$. parahaemolyticus. The results of the Challenge Experiment I (Figure 2) showed that within $24 \mathrm{~h}$ of addition of $V$. parahaemolyticus to the microcosm, concentrations of Halobacteriovorax increased by over four orders of magnitude, from $10^{5}$ to $10^{9.3} \mathrm{ml}^{-1}$. The Halobacteriovorax concentration peaked at $48 \mathrm{~h}$, leveled off between 48 and $72 \mathrm{~h}$ and decreased from 72 to $120 \mathrm{~h}$. The Halobacteriovorax concentrations at $0 \mathrm{~h}$ and $120 \mathrm{~h}$ were significantly different from one another $(t$-test, $P<0.0001)$. Concomitant to the increase in Halobacteriovorax was a significant decline of nearly four orders of magnitude in the $V$. parahaemolyticus concentration over the $120 \mathrm{~h}$ period ( $t$-test $P<0.0001) . \quad$ In contrast, in the $V$. parahaemolyticus control microcosm, which consisted of sterilized estuarine water (devoid of Halobacteriovorax and viruses) amended with $V$. parahaemolyticus, there was no statistically significant difference in the numbers of $V$. parahaemolyticus at the various time points (ANOVA).

The population dynamics of the Halobacteriovorax and $V$. parahaemolyticus were described well by a basic predator-prey model (Supplementary Figure S1).

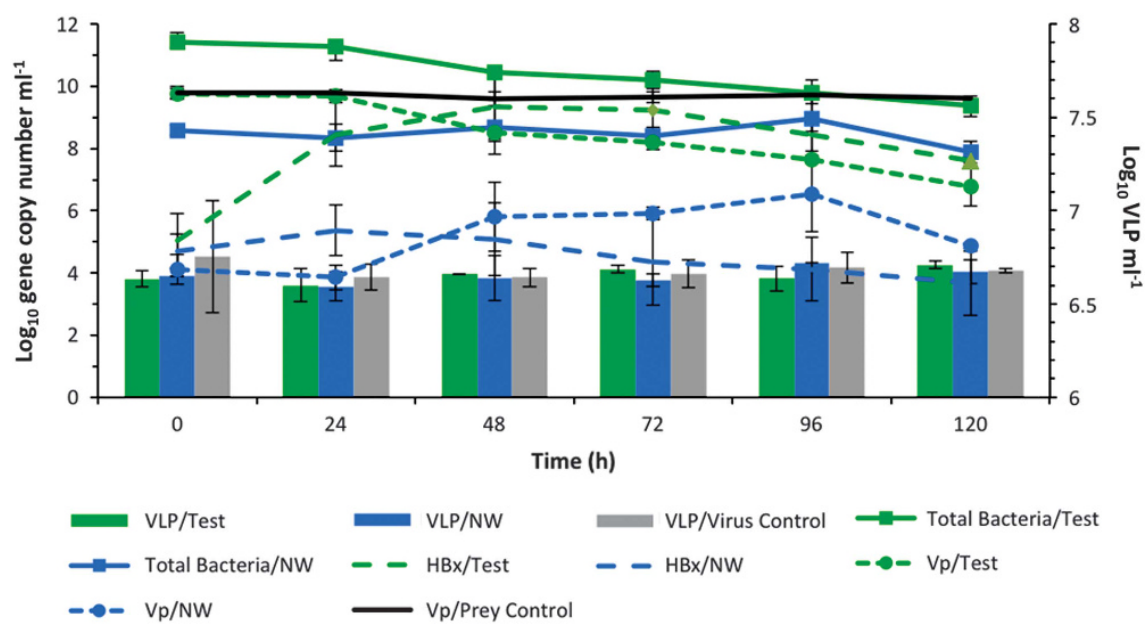

Figure 2 Challenge Experiment I. The population dynamics over a $120 \mathrm{~h}$ period of autochthonous Halobacteriovorax (HBx), virus-like particles (VLP), total bacteria and the added prey, $V$. parahaemolyticus (Vp), in the test microcosm consisting of estuarine water amended with Vp. Various control microcosms (Figure 1a) included Vp in autoclaved estuarine water (Vp/prey control), virus control consisting of filtered $(0.1 \mu \mathrm{m})$ estuarine water (devoid of Halobacteriovorax and other bacteria) with autochthonous viruses and amended with Vp, and the natural estuarine water (NW) control, which did not include the Vp amendment. Densities of total bacteria, HBx and Vp are inferred by gene copy number, as measured by qPCR. VLP abundance was determined by direct microscopic counts. All data represent the average from two experiments and error bars correspond to standard deviation from the average. For HBx, two copies of the 16S rRNA gene correspond to one cell, whereas the th (thermolabile hemolysin) gene is a species-specific marker for Vp and one copy corresponds to one cell. A supplementary figure (Supplementary Figure S4) provides information on the community dynamics of all four treatments as reflected by optical density units at $600 \mathrm{~nm}$. 
Based on that model, the rate of change of the logarithm of the Halobacteriovorax population should be a linear function of the numbers of $V$. parahaemolyticus, and that was found to be the case (Supplementary Figure S2), except at relatively low prey densities, when the natural mortality rate of the Halobacteriovorax began to increase, likely as a result of their increasing failure to find prey. Over the $120 \mathrm{~h}$ experiment, predation by Halobacteriovorax in the test microcosm and natural mortality of the prey in the control culture accounted for $93 \%$ and $5 \%$, respectively, of the $V$. parahaemolyticus mortality.

In contrast to the 4-log increase of Halobacteriovorax in the test microcosm, the virus-like particles densities increased by less than a factor of $10^{0.5}$. Although this increase was found to be statistically significant ( $t$-test, $P<0.05$ ), it was not considered relevant, as the virus-like particle counts after $120 \mathrm{~h}$ were not significantly different (ANOVA) from the virus-like particles counts in the virus control (with only $V$. parahaemolyticus and the native virus population) and NW control microcosms (without $V$. parahaemolyticus amendment). Also, the $V$. parahaemolyticus population in the virus control microcosm did not show a meaningful reduction as was the case in the test microcosm as shown by measurement of OD at $600 \mathrm{~nm}$ (Supplementary Figure S4). Not only did the $V$. parahaemolyticus in the virus control microcosm remain nearly constant throughout the duration of the experiment, but it was nearly identical to the $V$. parahaemolyticus pattern shown in the $V$. parahaemolyticus control microcosm with the prey and sterilized sea water.

The results from the NW control microcosm suggest that the interactions between viruses, Vibrio and Halobacteriovorax remained at steady state. There was no statistically significant change in either the Halobacteriovorax (ANOVA) or virus-like particle densities (ANOVA), and there was no decrease in the abundance of either the prey or the total bacteria (ANOVA).

To confirm the impact of Halobacteriovorax predation on $V$. parahaemolyticus, Challenge Experiment I was repeated, but with SIP (Challenge Experiment II SIP) using ${ }^{13} \mathrm{C}$ labeled $V$. parahaemolyticus prey (Figure 1b). The results revealed a pattern of population dynamics similar to that observed in Challenge Experiment I (Figure 3). In the SIP test microcosm with labeled $V$. parahaemolyticus, a marked decline in OD indicative of prey cell lysis was observed. A similar decline in OD was observed in the SIP control with unlabeled prey. This result was confirmed by the decline in the number of $V$. parahaemolyticus CFU and a corresponding increase in Halobacteriovorax PFU. In the prey control microcosm with only $V$. parahaemolyticus cells (no predators), the OD did not decline as markedly as it did in the SIP test and SIP control microcosms with predators (Figure 3). The virus control microcosm showed no signs of viral predation; the decline of OD was similar to the decline

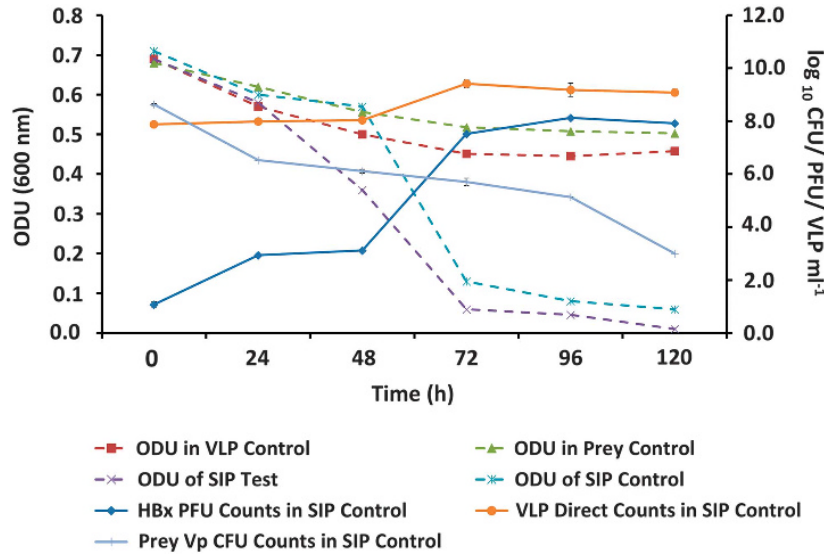

Figure 3 Challenge Experiment II. The population dynamics of Halobacteriovorax (HBx), viral like particles (VLP) and the prey bacterium, $V$. parahaemolyticus $(\mathrm{Vp})$, in the SIP ${ }^{13} \mathrm{C}$ labeled prey (SIP Test) and unlabeled prey (SIP Control) microcosms. The microcosms consisted of environmental water samples (filtered through $0.8 \mu \mathrm{m}$ filter) amended with $5 \times 10^{8}$ cells per ml of labeled or unlabeled Vp cells, respectively.

observed in the $V$. parahaemolyticus control microcosm without viruses. The similarity of the OD measurements in the SIP test and SIP control microcosms (Figure 3) confirmed that the decline of the $V$. parahaemolyticus was similar in both, the implication being that the ${ }^{13} \mathrm{C}$ label did not affect grazing on the prey.

To track the flow of the ${ }^{13} \mathrm{C}$ in the labeled $V$. parahaemolyticus test microcosm, DNA was extracted and amplified from the bacterial populations over the duration of the time series. When the ${ }^{13} \mathrm{C}$-labeled DNA was isolated from the unlabeled DNA on a cesium chloride gradient, analyses of the ${ }^{13} \mathrm{C}$-labeled band using denaturing gradient gel electrophoresis revealed Halobacteriovorax to be the predominantly labeled population (Figure 4). This implies that the Halobacteriovorax had preyed upon and acquired the ${ }^{13} \mathrm{C}$ from the labeled $V$. parahaemolyticus prey. Over time, the denaturing gradient gel electrophoresis bands of the Halobacteriovorax were observed to increase in intensity, indicative of increased predator population abundance, whereas the intensity of the bands corresponding to the $V$. parahaemolyticus prey diminished (Figure 4). This pattern is consistent with results observed in the previous experiment and provides direct experimental evidence and confirmation that Halobacteriovorax proliferated while preying on $V$. parahaemolyticus and was primarily responsible for mortality of the prey in the test microcosms.

\section{Discussion}

The response of native Halobacteriovorax and viral populations in estuarine water samples to an amendment of $V$. parahaemolyticus cells was 
496

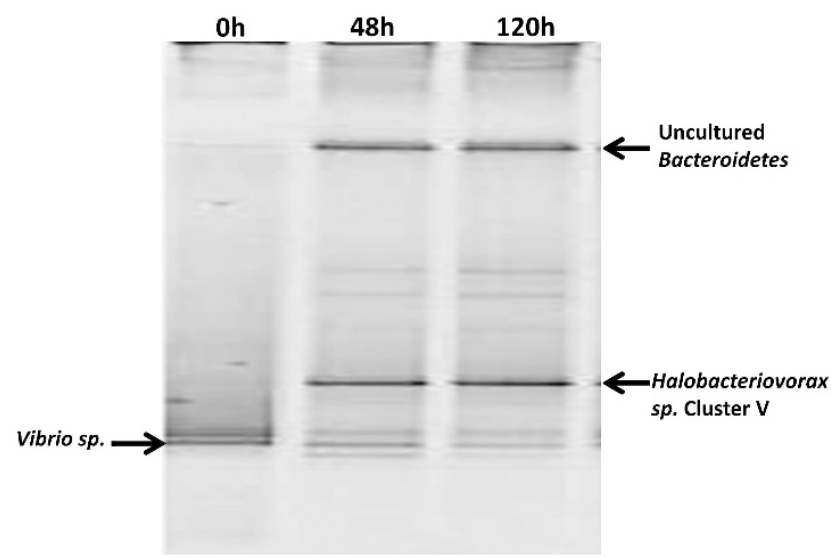

Figure 4 DGGE fingerprint profiles of amplified bacterial DNA from test microcosm with ${ }^{13} \mathrm{C}$ labeled $V$. parahaemolyticus prey using general Eubacterial primers. The Bacteroidetes band observed with the universal primer may represent the replacement community for the diminished $V$. parahaemolyticus population.

investigated in laboratory microcosms. The reaction of the Halobacteriovorax and its impact on the prey density mimicked that of a typical predator-prey interaction. In contrast, the viral response was uncharacteristic of a predator-prey interaction, as the viral population remained at or near steady state, and no significant reduction of the prey was observed in the virus control microcosms, as would have been expected if viruses had lysed the prey. These findings represent the strongest, most direct experimental evidence to date of the potential role of Halobacteriovorax in bacterial mortality. The fact that the experimental results concerned native predators in NWs adds relevance to the findings. Other investigators using different experimental models have also reported a reduction of prey bacteria by Halobacteriovorax and the potential of the predators to affect the mortality of susceptible bacterial populations in aquatic systems (Richards et al., 2012; Li et al., 2014; Wen et al., 2014). Richards et al. (2012) used several strains of $V$. parahaemolyticus and a strain of $V$. vulnificus as amendments to a natural seawater sample and observed a decline in their numbers along with an increase in Halobacteriovorax as we observed in the experiments described in this report.

The results of this and other studies show that high concentrations of BALOs are not critical for effective killing of their prey (Chen et al., 2011), as may be the case for viruses (for example, Wilcox and Fuhrman, 1994). The capability of 'rare' members of the microbial community (such as the BALOs) to grow and become common in a given niche at a particular time has been recognized and it has been suggested that rare organisms may act as 'seed banks' (PedrósAlió, 2006; Fuhrman, 2009). Such organisms may be relatively inactive and low in number until environmental changes present opportunities for them to increase in activity and abundance, becoming, in some cases, dominant. This appears to have been the case in this study, wherein a small BALO population in estuarine waters markedly increased following an influx of large numbers of a prey bacterium, $V$. parahaemolyticus. This result suggests that BALOs become dominant members of the bacterial community in response to environmental events that lead to high numbers of prey organisms in, for example, phytoplankton blooms (Guixa-Boixereu et al., 1999) and to the formation of 'bacterial hotspots' (Azam and Long, 2001; Stocker et al., 2008). We have previously demonstrated this potential experimentally by establishing natural bacterial community hotspots on an agarose surface; the hotspots elicited the migration and predation by native BALOs (Chauhan and Williams, 2006). Hotspots, which are large aggregates of bacteria attracted to micro-scale nutrient patches, may exceed $10^{7}$ cells per $\mathrm{ml}$ and are common in marine systems (Blackburn et al., 1998; Azam and Long, 2001; Stocker et al., 2008). Such hotspots are fertile ground for bacterial predators such as protists, viruses and BALOs and have important roles in biogeochemical cycles in the oceans (Blackburn et al., 1998; Azam and Long, 2001).

Based on current knowledge, we propose that both BALOs and viruses are effective in causing bacterial mortality, but not necessarily under similar conditions or at the same times and places. For example, BALOs are more efficient in predation at moderate temperatures and exhibit limited, if any, activity below $10^{\circ} \mathrm{C}$ (Williams, 1988). Viruses, however, appear to retain their potential to infect bacteria at low temperatures (Wilcox and Fuhrman, 1994). Also, viruses are reportedly more infective and replicate faster if matched with rapidly growing cells (Deng et al., 2012), whereas BALOs prefer prey in a slowly growing or stationary state. The low growth rate of the prey in our experiments may have accounted for the low viral activity observed in this study, which was conducted in NW microcosms with no added nutrients to support bacterial growth. Another possible reason for the low viral activity in this study was that $V$. parahaemolyticus-specific viral particles were either absent or present at concentrations too low for a successful encounter with the host and subsequent infection, although viruses that infect $V$. parahaemolyticus have been isolated from estuarine systems (Baross et al., 1978; Villa et al., 2012). Based on a review of several studies, Fuhrman (1999) concluded that viral activity may be low or non-existent among some groups of organisms and some habitats. Reports have also shown that virus infection in aquatic environments may frequently lead to lysogeny rather than immediate lysis of the prey cell (Weinbauer and Suttle, 1996).

The high motility of the BALOs, with speeds up to $160 \mu \mathrm{m} \mathrm{s}^{-1}$ (Lambert et al., 2011), nearly three or more times that of many other bacteria, gives them an advantage in seeking out and encountering their prey (Lambert et al., 2011). Also, BALOs typically prey on a wide range of Gram-negative bacteria 
(Rice et al., 1998; Chen et al., 2011) unlike the more host-specific and non-motile viruses. Irrespective of the causes for the low viral activity, our findings highlight the fact that under certain environmental conditions, Halobacteriovorax predation may be a more dominant factor in bacterial death than viral lysis.

The experimental conditions in this study were designed to simulate the natural environment as closely as possible by establishing microcosms with NW and native bacterial communities. The only treatment of the water samples prior to establishing the experimental and some control microcosms was pre-filtration to remove most protists, the intent of this study being to focus on BALO and viral predation. To establish the microcosms, the filtered water samples were amended with a high concentration $\left(10^{8} \mathrm{ml}^{-1}\right)$ of $V$. parahaemolyticus prey cells to efficiently elicit and amplify the predators' responses. Others have used this same approach in Halobacteriovorax predation experiments (Richards et al., 2012; Wen et al., 2014) and achieved the same pattern of reduction of the prey and increase in predator numbers. Some studies using viral microcosms have also involved high numbers of total bacteria (up to $3 \times 10^{7} \mathrm{ml}^{-1}$ ) (Guixa-Boixereu et al., 1999). Although such concentrations are high relative to natural abundances under many conditions, it is not uncommon for heightened concentrations of total bacteria and Vibrio spp. to occur in water bodies during warm summer months, especially during phytoplankton blooms, and in stagnant, warm, estuarine waters (Murray and Jackson, 1992; Wilcox and Fuhrman, 1994; Froelich et al., 2013). In the Potomac River, a tributary of the Chesapeake Bay, Hamdan and Jonas (2006) reported consistently finding over $1.3 \times 10^{7}$ cells per ml in certain periods and locations and in some cases found counts up to $4.5 \times 10^{7}$ cells per ml. Most of those bacteria were reported to be free-living. Harvey and Young (1980) and Sewell et al. (1981) have reported direct bacterial counts up to $1 \times 10^{8} \mathrm{ml}^{-1}$ in surface microlayers. The fact that Halobacteriovorax are also abundant in the surface microlayer (Williams, 1987) suggests that they prey on the large numbers of bacteria present. Although high concentrations of prey were used in this study, it should be noted that BALOs are typically capable of reducing prey concentrations via population dynamics similar to those shown in Figures 2 and 3 at prey concentrations as low as of $1 \times 10^{4} \mathrm{ml}^{-1}$, albeit over a longer time period (Ahmed, 2007; Richards et al., 2012; Li et al., 2014; Wen et al., 2014).

Another important aspect of BALO predation inferred based on its intraperiplasmic cell cycle (Starr and Baigent, 1966) is that it adds another dimension to the cycling of matter through the microbial loop. Although both BALOs and viruses have a role in recycling nutrients through the microbial loop, the mechanisms of recycling by the two predators are vastly different. Lytic infections of bacteria by viruses result in lysis of the prey cell and release of intracellular nutrients into the surrounding milieu for consumption by other bacteria and organisms (Middelboe et al., 1996; Weitz et al., 2015). In contrast, BALOs use much of the intracellular nutrient content of its prey for its own growth, leaving little to be released into the environment when the prey is lysed (Starr and Baigent, 1966). In this way, the prey nutrients are preserved at least for a time within the newly released BALO progeny and perhaps subsequently recycled to other organisms through grazing, viral infection or autolysis.

This report addresses the poorly understood and systematically neglected potential contribution of the predatory Halobacteriovorax to bacterial mortality and cycling of nutrients. The results provide direct evidence in support of our hypothesis that Halobacteriovorax have the potential to be important contributors to bacterial cell death and, under some conditions, may rival viruses as agents of bacterial mortality. These results are consistent with those of experiments we conducted with waters from several sites in the Chesapeake Bay (MD, USA), Atlantic Ocean coastal waters (FL, USA) and Apalachicola Bay (FL, USA).

The findings of this and other studies demonstrating the impact of BALO predation in aquatic systems (Li et al., 2011; Richards et al., 2012; Wen et al., 2014) argues for recognition of their potential role as biological agents of bacterial mortality along with viruses and protists. Johnke et al. (2014) have made a strong case for assessing the potential of multiple micro-predators rather than focusing on a single predator, as many previous studies have done. In this study, we have taken a small but important step consistent with their recommendation by considering both BALOs and viruses. A complete scenario of bacterial mortality cannot be developed until the collective role of BALOs and other predators is more fully assessed.

\section{Conflict of Interest}

The authors declare no conflict of interest.

\section{Acknowledgements}

We acknowledge the help of Cynthia Wang for her participation in preliminary experiments and editing of earlier versions of the manuscript. We gratefully acknowledge the support received from NSF grant nos. OCE 0455276, HRD 0932137, HRD 1056890 and NSF/NIH Ecology of Infectious Disease Program OCE 0812913.

\section{References}

Ahmed M. (2007). Isolation, characterization and possible biocontrol application of Bdellovibrionaceae (BD) isolated from NZ sources. Doctoral Thesis, Institute of Technology and Engineering, Massey University. 
Amaral-Zettler L, Artigas LF, Baross J, Bharathi L, Boetius A, Chandramohan D et al. (2010). A global census of marine microbes. Life in the world's Oceans: Diversity, Distribution and Abundance. Blackwell Publishing Ltd: Oxford, 223-245.

Azam F, Long RA. (2001). Oceanography: sea snow microcosms. Nature 414: 495-498.

Baross JA, Liston J, Morita RY. (1978). Incidence of Vibrio parahaemolyticus bacteriophages and other Vibrio bacteriophages in marine samples. Appl Environ Microbiol 36: 492-499.

Blackburn N, Fenchel T, Mitchell J. (1998). Microscale nutrient patches in planktonic habitats shown by chemotactic bacteria. Science 282: 2254-2256.

Chauhan A, Williams HN. (2006). Response of Bdellovibrio and like organisms (BALOs) to the migration of naturally occurring bacteria to chemoattractants. Curr Microbiol 53: 516-522.

Chen F, Lu JR, Binder BJ, Liu YC Hodson RE. (2001). Application of digital image analysis and flow cytometry to enumerate marine viruses stained with SYBR Gold. Appl Environ Microbiol 67: 539-545.

Chen H, Athar R, Zheng G, Williams HN. (2011). Prey bacteria shape the community structure of their predators. ISME J 5: 1314-1322.

Crothers-Stomps C, Høj L, Bourne D, Hall M, Owens L. (2010). Isolation of lytic bacteriophage against Vibrio harveyi. J Appl Microbiol 108: 1744-1750.

Davidov Y, Friedjung A, Jurkevitch E. (2006). Structure analysis of a soil community of predatory bacteria using culture-dependent and culture-independent methods reveals a hitherto undetected diversity of Bdellovibrio-and-like organisms. Environ Microbiol 8: 1667-1673.

Deng L, Gregory A, Yilmaz S, Poulos BT, Hugenholtz P, Sullivan MB. (2012). Contrasting life strategies of viruses that infect photo-and heterotrophic bacteria, as revealed by viral tagging. MBio 3. doi:10.1128/ mBio.00373-12.

Fenton A, Kanna M, Woods R, Aizawa S-I, Sockett R. (2010). Shadowing the actions of a predator: backlit fluorescent microscopy reveals synchronous nonbinary septation of predatory Bdellovibrio inside prey and exit through discrete bdelloplast pores. J Bacteriol 192: 6329-6335.

Froelich B, Williams T, Noble RT, Oliver JD. (2013). Apparent loss of Vibrio vulnificus in North Carolina oysters coincides with drought-induced increase in salinity. Appl Environ Microbiol 78: 3885-3889.

Fuhrman JA, Noble RT. (1995). Viruses and protists cause similar bacterial mortality in coastal seawater. Limnol Oceanogr 40: 1236-1242.

Fuhrman JA. (1999). Marine viruses and their biogeochemical and ecological effects. Nature 399: 541-548.

Fuhrman JA. (2009). Microbial community structure and its functional implications. Nature 459: 193-199.

Guixa-Boixereu N, Lysnes K, Pedrós-Alió C. (1999). Viral lysis and bacterivory during a phytoplankton bloom in a coastal water microcosm. Appl Environ Microbiol 65: 1949-1958.

Hamdan LJ, Jonas RB. (2006). Seasonal and interannual dynamics of free-living bacterioplankton and microbially labile organic carbon along the salinity gradient of the Potomac River. Estuar Coast 29: 40-53.
Harvey R, Young L. (1980). Enrichment and association of bacteria and particulates in salt marsh surface water. Appl Environ Microbiol 39: 894-899.

Johnke J, Cohen Y, de Leeuw M, Kushmaro A, Jurkevitch E, Chatzinotas A. (2014). Multiple micro-predators controlling bacterial communities in the environment. Curr Opin Biotechnol 27: 185-190.

Koval SF, Williams HN, Stine OC. (2014). Reclassification of Bacteriovorax marinus as Halobacteriovorax marinus gen. nov., comb. nov. and Bacteriovorax litoralis as Halobacteriovorax litoralis comb. nov.; description of Halobacteriovoraceae fam. nov. in the class Deltaproteobacteria. Int J Syst Evol Microbiol 0: 070201-070200.

Lambert C, Fenton AK, Hobley L, Sockett RE. (2011). Predatory Bdellovibrio bacteria use gliding motility to scout for prey on surfaces. J Bacteriol 193: 3139-3141.

Li H, Liu C, Chen L, Zhang X, Cai J. (2011). Biological characterization of two marine Bdellovibrio-and-like organisms isolated from Daya bay of Shenzhen, China and their application in the elimination of Vibrio parahaemolyticus in oyster. Int J Food Microbiol 151: 36-43.

Li H, Chen C, Sun Q, Liu R, Cai J. (2014). Bdellovibrio and like organisms enhanced growth and survival of penaeus monodon and altered bacterial community structures in its rearing water. Appl Environ Microbiol 80: $6346-6354$.

Middelboe M, Jorgensen N, Kroer N. (1996). Effects of viruses on nutrient turnover and growth efficiency of noninfected marine bacterioplankton. Appl Environ Microbiol 62: 1991-1997.

Murray AG, Jackson GA. (1992). Viral dynamics: a model of the effects of size, shape, motion and abundance of single-celled planktonic organisms and other particles. Mar Ecol Prog Ser 89: 103-116.

Muyzer G, Teske A, Wirsen C, Jannasch H. (1995). Phylogenetic relationships of Thiomicrospira species and their identification in deep-sea hydrothermal vent samples by denaturing gradient gel electrophoresis of 16S rDNA fragments. Arch Microbiol 164: 165-172.

Padmanabhan P, Padmanabhan S, DeRito C, Gray A, Gannon D, Snape J et al. (2003). Respiration of 13Clabeled substrates added to soil in the field and subsequent 16S rRNA gene analysis of 13C-labeled soil DNA. Appl Environ Microbiol 69: 1614-1622.

Pedrós-Alió C. (2006). Marine microbial diversity: can it be determined? Trends Microbiol 14: 257-263.

Pineiro SA, Sahaniuk GE, Romberg E, Williams HN. (2004). Predation pattern and phylogenetic analysis of Bdellovibrionaceae from the Great Salt Lake, Utah. Curr Microbiol 48: 113-117.

Pineiro SA, Stine OC, Chauhan A, Steyert SR, Smith R, Williams HN. (2007). Global survey of diversity among environmental saltwater Bacteriovoracaceae. Environ Microbiol 9: 2441-2450.

Proctor LM, Fuhrman JA. (1990). Viral mortality of marine bacteria and cyanobacteria. Nature 343: 60-62.

Rice TD, Williams HN, Turng BF. (1998). Susceptibility of bacteria in estuarine environments to autochthonous bdellovibrios. Microb Ecol 35: 256-264.

Richards GP, Fay JP, Dickens KA, Parent MA, Soroka DS, Boyd EF. (2012). Predatory bacteria as natural modulators of Vibrio parahaemolyticus and Vibrio vulnificus in seawater and oysters. Appl Environ Microbiol 78: $7455-7466$. 
Richards GP, Watson MA, Boyd EF, Burkhardt W, Lau R, Uknalis J et al. (2013). Seasonal levels of the Vibrio predator bacteriovorax in atlantic, pacific, and gulf coast seawater. Int J Microbiol 2013: 375371.

Sewell LM, Bitton G, Bays JS. (1981). Evaluation of membrane adsorption-epifluorescence microscopy for the enumeration of bacteria in coastal surface films. Microb Ecol 7: 365-369.

Starr MP, Baigent NL. (1966). Parasitic interaction of Bdellovibrio bacteriovorus with other bacteria. J Bacteriol 91: 2006-2017.

Stocker R, Seymour JR, Samadani A, Hunt DE, Polz MF. (2008). Rapid chemotactic response enables marine bacteria to exploit ephemeral microscale nutrient patches. Proc Natl Acad Sci USA 105: 4209-4214.

Sutton D, Besant P. (1994). Ecology and characteristics of bdellovibrios from three tropical marine habitats. Mar Biol 119: 313-320.

Taylor VI, Baumann P, Reichelt JL, Allen RD. (1974). Isolation, enumeration, and host range of marine Bdellovibrios. Arch Microbiol 98: 101-114.

Tsai A, Gong G-C, Hung J. (2013). Seasonal variations of virus-and nanoflagellate-mediated mortality of heterotrophic bacteria in the coastal ecosystem of subtropical western Pacific. Biogeosciences 10: 3055-3065.

Varon M, Shilo M. (1980). Ecology of aquatic bdellovibrios. Adv Aquat Microbiol 2: 1-48.

Villa AA, Kropinski AM, Abbasifar R, Abbasifar A, Griffiths MW. (2012). Genome sequence of temperate Vibrio parahaemolyticus bacteriophage vB_VpaS MAR10. J Virol 86: 13851-13852.
Weinbauer MG, Suttle CA. (1996). Potential significance of lysogeny to bacteriophage production and bacterial mortality in coastal waters of the gulf of Mexico. Appl Environ Microbiol 62: 4374-4380.

Weinbauer MG, Höfle MG. (1998). Significance of viral lysis and flagellate grazing as factors controlling bacterioplankton production in a eutrophic lake. Appl Environ Microbiol 64: 431-438.

Weitz JS, Stock CA, Wilhelm SW, Bourouiba L, Coleman ML, Buchan A et al. (2015). A multitrophic model to quantify the effects of marine viruses on microbial food webs and ecosystem processes. ISME J.

Wen C, Xue M, Liang H, Zhou S. (2014). Evaluating the potential of marine Bacteriovorax sp. DA5 as a biocontrol agent against vibriosis in Litopenaeus vannamei larvae. Vet Microbiol 173: 84-91.

Wilcox RM, Fuhrman JA. (1994). Bacterial viruses in coastal seawater: lytic rather than lysogenic production. Mar Ecol Prog Ser 114: 35-35.

Williams H. (1987). The recovery of high numbers of bdellovibrios from the surface water microlayer. Can J Microbiol 33: 572-575.

Williams H. (1988). A study of the occurrence and distribution of bdellovibrios in estuarine sediment over an annual cycle. Microb Ecol 15: 9-20.

Williams HN. (1979). Cultural, immunologic and ecologic studies of marine bdellovibrios isolated from the Atlantic Ocean and the Chesapeake Bay. PhD thesis, University of Maryland: Baltimore, MD, USA.

Supplementary Information accompanies this paper on The ISME Journal website (http://www.nature.com/ismej) 